\title{
Inflammatory Markers and Mean Platelet Volume in Patients with Slow Coronary Flow and Its Relationship with Clinical Presentation
}

Walaa F Abd-Alaziz ${ }^{1}$, Ali Ibrahim ${ }^{4}$, Mansour Elsayed ${ }^{2}$, Abdulaziz Aboshahba ${ }^{134}$, Ibrahim Altaj $^{4}$, Ayman Ghoniem $^{5,6}$, Saifeddin Ibrahim ${ }^{4}$ and Mohamed Alassal ${ }^{4,7 *}$

${ }^{1}$ Department of Cardiology, Menoufia University, Egypt

${ }^{2}$ Department of Clinical Pathology, Menoufia University, Egypt

${ }^{3}$ Department of Cardiology, Alazhar University, Egypt

${ }^{4}$ PAAMCC Cardiac Center, KSA

${ }^{5}$ Department of Cardiothoracic Surgery, Alazhar University, Egypt

${ }^{6}$ Department of Cardiothoracic Surgery, Al-Moasa Specialist Hospital, KSA

${ }^{7}$ Department of Cardiothoracic Surgery, Benha University, Egypt

Submission: March 12, 2018; Published: April 26, 2018

*Corresponding author: Mohamed Alassal, Department of Cardiothoracic Surgery, Faculty of Medicine, Benha University, Benha, Egypt, Email: dmohamedabdelwahab@gmail.com

Abstract

Background and aim of the work: Platelets play a role in the pathogenesis of atherosclerotic complications by contributing to thrombus formation or plaque rupture. There is evidence that inflammation plays an important role in the initiation, development as well as evolution of atherosclerosis, suggesting that atherosclerosis is an inflammatory disease. The aim of this study is to evaluate the effect of mean platelet volume (MPV) and some inflammatory markers on patients with slow coronary flow (SCF) and its possible relationship with clinical presentation.

Methodology: This study included thirty patients with coronary slow flow detected by coronary angiography via Thrombosis in Myocardial Infarction (TIMI) frame count method and fifteen patients with normal coronary arteries were selected as control group. All patients group and control group underwent Legal consent, complete history taking, Resting 12 leads ECG, CBC, fasting blood glucose level, serum triglycrides, LDL, HDL, Mean platelet volume, C-reactive protein (CRP), ESR, interleukin 6 (IL6) at admission and after 6 months of treatment with antiplatlet and antidyslipidemic. Transthoracic Echocardiography and Coronary angiography done to diagnose slow coronary flow by TIMI frame count.

Results: Of this study found that; Interleukin- 6 and C-reactive protein as well as mean platelet volume were increased in patients with coronary slow flow in comparison to control group. Interleukin 6 and C-reactive protein were decreased after six months of antidyslipidemic drugs in comparison to their values at the start.

Conclusion: increased concentrations of inflammatory markers in patients with SCF may be an indicator of endothelial activation and inflammation and are likely to be in the causal pathway involving in SCF. Therefore, an attention should be paid to this unique phenomenon. Our findings showed also that MPV is increased in patients with SCF, suggesting an altered platelet reactivity and aggregation which require effective anti-platelet therapy in this patient subgroup.

Abbreviations: VSMC: Vascular Smooth Muscle Cells; MI: Myocardial Infarctions; LDL: Low-Density Lipoprotein; CRP: C-Reactive Protein; IL-6: Interleukin-6; HDL: High-Density Lipoprotein; PPAR-a: Peroxisome Proliferator Activated Receptor alpha; PAMPs: Pathogen Associated Molecular Patterns; PRRs: Pattern Recognition Receptors; TLRs: Toll-Like Receptors; LIF: Leukemia Inhibitory Factor; STATs: Signal Transducers and Activators of Transcription; IL-11: Interleukin -11; CNTF: Ciliary Neurotrophic Factor; CT-1: Cardiotrophin-1; CLC: CardiotrophinLike Cytokine; OSM: Onco Statin M; SAA: Serum Amyloid A; A-SAAs: Acute-Phase Serum Amyloid A Proteins; LPS: Lipopolysaccharide; TNF: Tumor Necrosis Factor; IBD: Inflammatory Bowel Disease; MPV: Mean Platelet Volume; ADP: Adenosine Diphosphate; TFC: TIMI Frame Count; TIMIM: Thrombolysis In Myocardial Infarction; CTFC: Corrected TIMI Frame Count; RI: Right Inferior; LAD: Left Anterior Descending Artery; LCX: Left Circumflex Artery; DSA: Digital Subtraction Angiography; SCF: Slow Coronary Flow; CSFP: Coronary Slow Flow Phenomenon; NTproBNP: N-Terminal Pro- Brain Natriuretic Peptide; RCA: Right Coronary Artery; ICAM-1: Intercellular Adhesion Molecule-1; VCAM-1: Vascular Cell Adhesion Molecule-1; NO: Nitric Oxide; EDRF: Endothelium-Derived Relaxing Factor; SA: Stable Angina; UA: Unstable Angina; TC: Total Colesterol; TG: Triglycrides; ESR: Erythrocyte Sedimentation Rate; DD: Diastolic Dysfunction; RWMA: Resting Wall Motion Abnormality 


\section{Introduction}

Platelets play a role in the pathogenesis of atherosclerotic complications by contributing to thrombus formation or plaque rupture [1]. Larger platelets are hemostatically more active and are a risk factor for developing coronary thrombosis, leading to unstable coronary syndromes [2]. Platelet volume is a marker of platelet activation and function, and is measured using mean platelet volume (MPV) [2,3]. The slow coronary flow (SCF) phenomenon is an angiographic observation characterized by angiographically normal or near-normal coronary arteries with delayed opacification of the distal vasculature [4].

It has been reported that coronary endothelial dysfunction play an important pathogenetic role in patients with SCF. However the precise mechanisms responsible for this microvascular endothelial dysfunction in patients with SCF are still unknown [5].

Although atherosclerosis has been considered to be multifactorial disease in which genetic, environmental, metabolic factors have been implicated, the gaps remain in our knowledge of the etiopathogenesis of atherosclerosis. Inflammation plays a role as an important pathogenic insulting factor for various cardiovascular diseases, along with coronary heart disease. Therefore, the neutrophil-to-lymphocyte ratio (NLR) has been reported to effect various inflammatory diseases, including some cardiovascular diseases $[3,6]$. There is mounting evidence that inflammation plays an important role in the initiation, development as well as evolution of atherosclerosis, suggesting that atherosclerosis is an inflammatory disease $[7,8]$. Plateletto-lymphocyte ratio (PLR) was higher in patients with CSFP, and we also showed that PLR was significantly and independently associated with CSFP.

In addition, a large amount of data indicated that C-reactive protein (CRP) is a sensitive marker of underlying systemic inflammation. CRP increases among men and women at risk for future cardiovascular events, and the addition of CRP testing to standard lipid screening seems to provide an improved method to determine vascular risk $[9,10]$. These data, as well as accumulating evidence that CRP may have direct inflammatory effects at the endothelial levels. Besides, among pro-inflammatory cytokines, interleukin-6 (IL-6) is one of the most important factors and has multiple important effects in human pathophysiology. In previous studies, the data showed that an enhanced production of IL- 6 by monocytes in response to CRP in patients with unstable angina [7]. Moreover, IL-6 is a powerful stimulus for CRP production [11]. Based on those observations, Jian-Jun Li [12], hypothesis that an inflammatory process may be associated with the development of SCF.

\section{Patients and Methods}

This study included thirty consecutive patients with coronary slow flow (CSF) detected by coronary angiography via the Thrombosis In Myocardial Infarction (TIMI) frame count and fifteen patients with normal coronary angiography who were attending the cardiology department of Al Hussein and Elsayed Galal University Hospitals.

Inclusion criteria: 30 patients who did not receive any anti-platelets or anti-dyslipidemic medications before with SCF detected by coronary angiography via TIMI frame count method were enrolled in this study. Patients with coronary artery diseases (lesions $<30 \%$ ) are included in this study and 15 patients with normal coronary arteries are selected for the control group.

Exclusion criteria: we excluded all Patients with evidence of obstructive coronary artery diseases (lesions $>30 \%$ ), with Valvular heart disease; Congestive heart failure; Echocardiographically proven left ventricular hypertrophy; with untreated thyroid disease; Sinus node dysfunction or conduction disturbance; Estrogen replacement therapy; uncontrolled hypertension; recent major operation, (less than 3 months) and Patients with Coronary artery ectesia.

All patient underwent the following: Complete history taking; Resting 12 leads ECG; CBC, fasting blood glucose level, serum triglycerides, LDL, HDL, Mean platelet volume, C-reactive protein (CRP), ESR, interleukin 6 (IL6), before and after 6 months of anti-platelets, transthoracic Echocardiography, Coronary angiography to diagnose slow coronary flow by TIMI frame count. Coronary angiography was performed using the standard Judkin's techniques, and the results were analyzed by at least 2 interventional physicians according to our previous study. Contrast used in angiography of this study is Iopromide (Ultravist-370, and teleberex). Coronary flow rates of all subjects were determined by TIMI frame count because this method is simple, reproducible, objective and quantitative index of coronary flow velocity. TIMI frame count was determined for each major coronary artery in each patient and control subject according to the method first described by Gibson et al. [13].

EDTA-anticoagulated peripheral blood sample were taken after 12-h overnight t-fast at baseline (before coronary angiography). The plasma was obtained after a centrifugation of $3000 \mathrm{rpm}$ at $4{ }^{\circ} \mathrm{C}$ for $15 \mathrm{~min}$. The concentrations of CRP were determined using immunoturbidometry (Beckmann Assay 360) IL-6 was measured with a commercial assay kit (human IL-6, ELISA kit). IL-6 measurements were performed from plasma. The assay employs an antibody specific for human interleukin- 6 coated on a 96-well plate standards, samples and biotinylated anti-human IL- 6 are pipetted into the wells and IL- 6 present in a sample is captured by the antibody immobilized to the wells and by the biotinylated IL- 6 specific detedction antibody; after washing away unbound biotinylated antibody, HRP-conjugated streptavidin is pippted to the wells. The wells are again washed. Following this second step, TMB substrate solution is added to the wells, resulting in color development proportional to the amount of IL- 6 bound. The stop solution changes the color from blue to yellow, and the intensity of the color is measured $450 \mathrm{~nm}$. Blood 
samples were collected from the patients after a 12-hr overnight fasting. All routine biochemical tests were carried out on an autoanalyser, $\mathrm{CBC}$, fasting blood glucose level, serum triglycrides, LDL, HDL, Mean platelet volume.

Statistical analysis of the data: The collected data was organized, tabulated and statistically analyzed using statistical package of social science (SPSS) version 16 (SPSS Inc, USA). For qualitative data, frequency and percent distribution were calculated and for comparison between groups, chi-square (X2) test was used. For quantitative data, mean, minimum, maximum and standard deviation were calculated and for comparison between two groups, the independent sample ( $t$ ) test was calculated; for comparison between more than two groups, the one way analysis of variance (ANOVA) was calculated. For comparison between the same groups at two different points of time, paired samples $(\mathrm{t})$ test was calculated. For correlation between two parameters, the spearman's correlation coefficient (r) was calculated; it was mild if $r<0.3$; moderate if $r \geq 0.3$ and $\leq 0.7$, powerful if $r>7$. For interpretation of results $p$ value $\leq 0.05$ was considered significant.

\section{Results}

The present study included 45 subjects, 28 of them (62.2\%) were males and $17(37.8 \%)$ were females with male to female ratio of 1.65 and there was statistically insignificant difference between study and control groups as regard sex distribution (males represent $63.3 \%$ of the study group compared to $60.0 \%$ of the control group). As regard age, it ranged from 37 to 65years with a mean of $52.84 \pm 7.36$ years and there was statistically insignificant increase in age of control group in comparison to study group ( $53.00 \pm 8.07$ vs $52.76 \pm 7.12$ years old respectively). As regard risk factors, diabetes was reported in 26 cases (57.8\%), hypertension reported in 29 cases (64.4\%), obesity reported in 15 cases $(33.3 \%)$ and smoking reported in 21 cases (46.7\%) and there was statistically insignificant difference between patients and control groups as regard risk factors (Table 1, Figure 1).

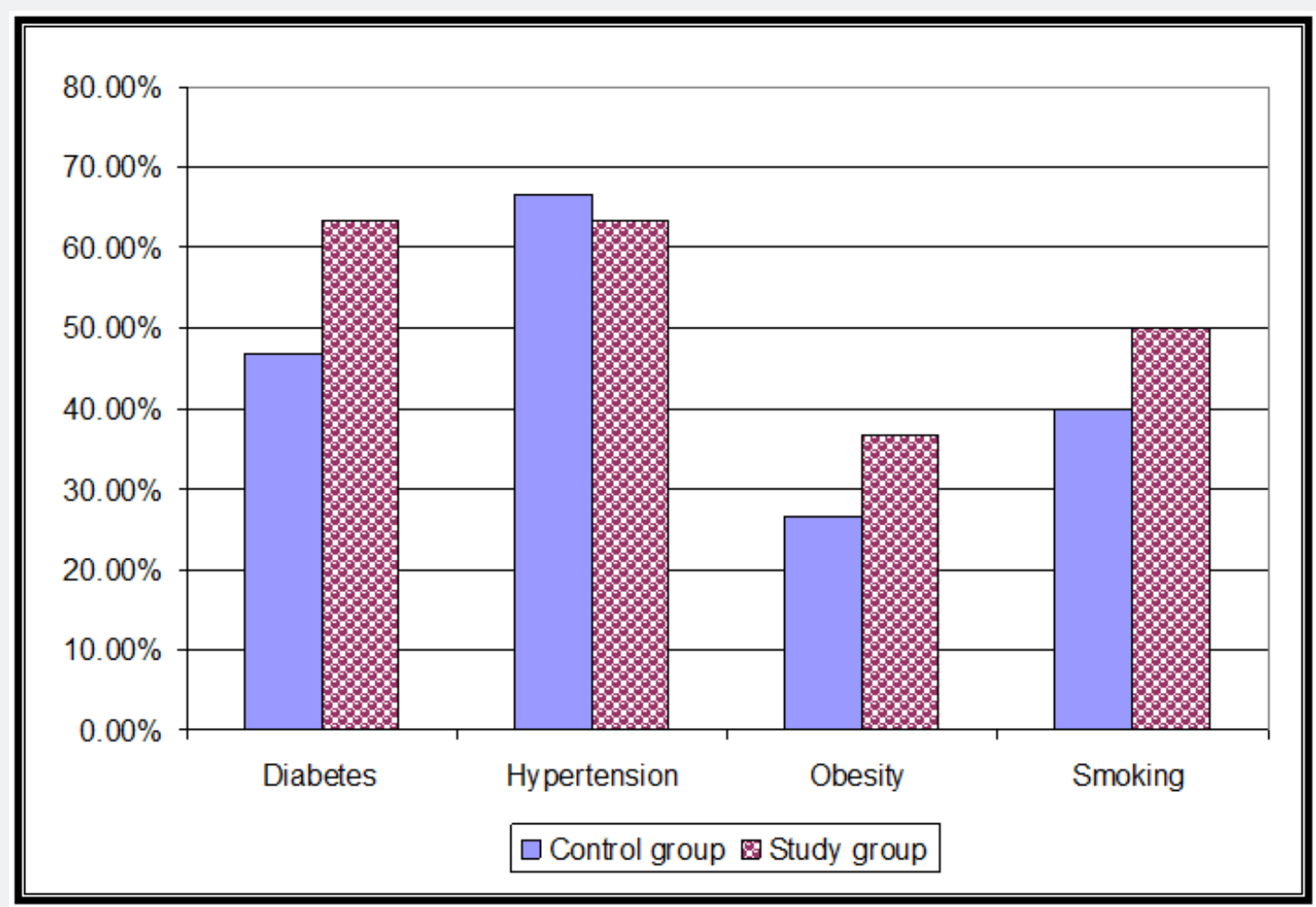

Figure 1: Comparison between patients and control groups as regard risk factors.

Table 1: Comparison between study and control group as regard general characteristic and risk factors.

\begin{tabular}{|c|c|c|c|c|}
\hline & Control Group & Study Group & t Test & P Value \\
\hline Gender Male $(\mathrm{n}, \%)$ & $9(60.0 \%)$ & $19(63.3 \%)$ & 0.047 & $0.82(\mathrm{NS})$ \\
\hline Age $($ mean \pm SD) & $53.00 \pm 8.07$ & $52.76 \pm 7.12$ & 0.1 & $0.92(\mathrm{NS})$ \\
\hline Diabetes (n,\%) & $7(46.7 \%)$ & $19(63.3 \%)$ & 1.13 & $0.28(\mathrm{NS})$ \\
\hline Hypertension (n,\%) & $10(66.7 \%)$ & $19(63.3 \%)$ & 0.048 & $0.82(\mathrm{NS})$ \\
\hline Obesity (n,\%) & $4(26.7 \%)$ & $11(36.7 \%)$ & 0.045 & $0.50(\mathrm{NS})$ \\
\hline Smoking $(\mathrm{n}, \%)$ & $6(40.0 \%)$ & $15(50.0 \%)$ & 0.04 & $0.52(\mathrm{NS})$ \\
\hline
\end{tabular}


As regard clinical presentation it was in form of stable angina 14 cases (31.1\%); atypical chest pain 14 cases (31.1\%); unstable angina 15 cases $(33.3 \%)$ and non ST segment MI 2 cases (4.4\%) and there was statistically insignificant difference between patients and control groups as regard clinical presentation. As regard LDL, it ranged from 83 and $170 \mathrm{mg} \%$ with a mean of $123.98 \pm 23.05$ and there was statistically significant increase in study group in comparison to control group $(132.43 \pm 21.00$ vs $107.07 \pm 17.24$ respectively). In addition, total cholesterol ranged between 73 and $270 \mathrm{mg} \%$ with a mean of $189.89 \pm 36.39$ and there was statistically significant increase in study in comparison to control group ( $204.13 \pm 30.28$ vs $161.40 \pm 30.95$ respectively). On the other hand, there was statistically insignificant difference between study and control groups as regard LDL and triglycerides serum levels. As regard fasting blood sugar ranged between 70 and $157 \mathrm{mg} \%$ with a mean of $108.1 \pm 26.98$ and there was statistically significant increase in the study in comparison to control group $(112.80 \pm 27.20$ vs $98.73 \pm 24.76 \mathrm{mg} / \mathrm{dl}$ respectively). As regard ESR ranged between 7 and 45 with a mean of $20.26 \pm 9.0$ and there was statistically insignificant increase in the study in comparison to control group ( $21.86 \pm 9.28$ vs $17.06 \pm 7.74$ respectively). On the other hand, CRP ranged from 2.10 to 6.30 with a mean of $4.43 \pm 1.16$ and there was statistically significant increase of CRP in study group in comparison to control group ( $4.91 \pm 0.93$ versus $3.48 \pm 1.00$ respectively) (Table 2 ).

Table 2: Comparison between study and control group as regard laboratory finding.

\begin{tabular}{|c|c|c|c|c|}
\hline & Control Group & Study Group & Test & P Value \\
\hline LDL & $107.07 \pm 17.24$ & $132.43 \pm 21.0$ & 4.03 & $0.00(\mathrm{~S})$ \\
\hline HDL & $51.73 \pm 6.20$ & $16.86 \pm 8.65$ & 1.93 & $0.059(\mathrm{NS})$ \\
\hline TC & $161.40 \pm 30.95$ & $204.13 \pm 30.28$ & 4.42 & $0.00(\mathrm{~S})$ \\
\hline TG & $133.07 \pm 28.36$ & $149.23 \pm 7.12$ & 1.79 & $0.079(\mathrm{NS})$ \\
\hline FBS & $98.73 \pm 24.76$ & $112.80 \pm 27.20$ & 1.68 & $0.101(\mathrm{NS})$ \\
\hline ESR & $17.06 \pm 8.07$ & $21.86 \pm 9.28$ & 1.72 & $0.092(\mathrm{NS})$ \\
\hline CRP & $3.48 \pm 1.0$ & $4.91 \pm 0.93$ & 4.72 & $0.001(\mathrm{~S})$ \\
\hline MPV & $9.44 \pm 1.64$ & $12.26 \pm 1.69$ & 5.32 & $0.001(\mathrm{~S})$ \\
\hline IL 6 & $13.98 \pm 6.55$ & $164.29 \pm 259.71$ & 2.23 & $0.031(\mathrm{~S})$ \\
\hline
\end{tabular}

As regard ECG was normal in 11 cases (24.4\%), flat T wave in 2 cases (4.4\%), $\mathrm{T}$ wave inversion in 16 cases $(35.6 \%)$ and ST depression in 16 cases (35.6\%) and there was statistically insignificant difference between study and control group as regard ECG findings. As regard Echocardiogram was within normal range LVEF\% in 17 cases (37.8\%); DD grade I in 18 cases (40.0\%), DD grade III in 6 cases (13.3\%) and RWMA in 4 cases (8.9\%), and there was statistically insignificant difference between patients group and control group as regard Echocardiogram findings.

As regard MPV ranged between 7.30 and $15.20 \mathrm{fl}$ with a mean of $11.32 \pm 2.13$ with statistically significant increase in study group in comparison to control $(12.26 \pm 1.69$ vs $9.44 \pm 1.64$ respectively). As regard interleukin 6 it ranged between 3.40 and 1000.0 pg with a mean $114.19 \pm 222.7$ and there was statistically significant increase in study group in comparison to control group (164.29 \pm 259.71 vs $13.98 \pm 6.55$ respectively) (Table 2 ).

This study demonstrates that there was statistically significant decrease in MPV, CRP and IL- 6 after 6 months in comparison with their values at the start (Table 3 ). In addition there was statistically significant variance between different clinical presentations as regard LDL and HDL. On the other hand, there was statistically insignificant variance between different clinical presentations as regard TC and TG, fasting blood sugar and ESR (Table 4).

Table 3: Comparison between values at admission and after 6 months of MPV, CRP and IL 6 in the patients group.

\begin{tabular}{|c|c|c|c|c|c|c|}
\hline \multirow{2}{*}{} & \multicolumn{3}{|c|}{ At the Start } & \multicolumn{2}{c|}{ After 6 months } & \multirow{2}{*}{ Paired (t) } \\
\cline { 2 - 6 } & Mean & S. D & Mean & S. D & & \\
\hline MPV & 12.26 & 1.69 & 11.35 & 1.67 & 4.28 & $<0.001(\mathrm{~S})$ \\
\hline CRP & 4.91 & 0.93 & 4.45 & 0.82 & 5.55 & $<0.001(\mathrm{~S})$ \\
\hline IL 6 & 164.29 & 259.71 & 75.47 & 112 & 2.58 & $0.015(\mathrm{~S})$ \\
\hline
\end{tabular}


Table 4: Correlation between different clinical presentation as regard.

\begin{tabular}{|c|c|c|c|c|c|}
\hline & SA & Atypical & UA & Non ST & P Value \\
\hline LDL & $134.12 \pm 17.90$ & $115.38 \pm 21.96$ & $141.75 \pm 18.25$ & $138.00 \pm 7.07$ & 3.2 \\
\hline HDL & $45.00 \pm 8.01$ & $54.50 \pm 7.13$ & $42.91 \pm 7.82$ & $47.50 \pm 3.53$ & $0.04(\mathrm{~S})$ \\
\hline TC & $200.38 \pm 25.48$ & $186.50 \pm 25.00$ & $219.75 \pm 33.00$ & $196.00 \pm 5.65$ & 2.34 \\
\hline TG & $159.00 \pm 33.12$ & $136.88 \pm 29.75$ & $148.00 \pm 25.21$ & $167.00 \pm 5.65$ & 1.09 \\
\hline FBS & $120.0 \pm 23.50$ & $93.50 \pm 24.24$ & $116.08 \pm 27.47$ & $141.50 \pm 3.53$ & $0.09(\mathrm{NS})$ \\
\hline ESR & $21.50 \pm 11.62$ & $23.12 \pm 11.99$ & $22.41 \pm 6.28$ & $15.00 \pm 0.00$ & $0.063(\mathrm{NS})$ \\
\hline
\end{tabular}

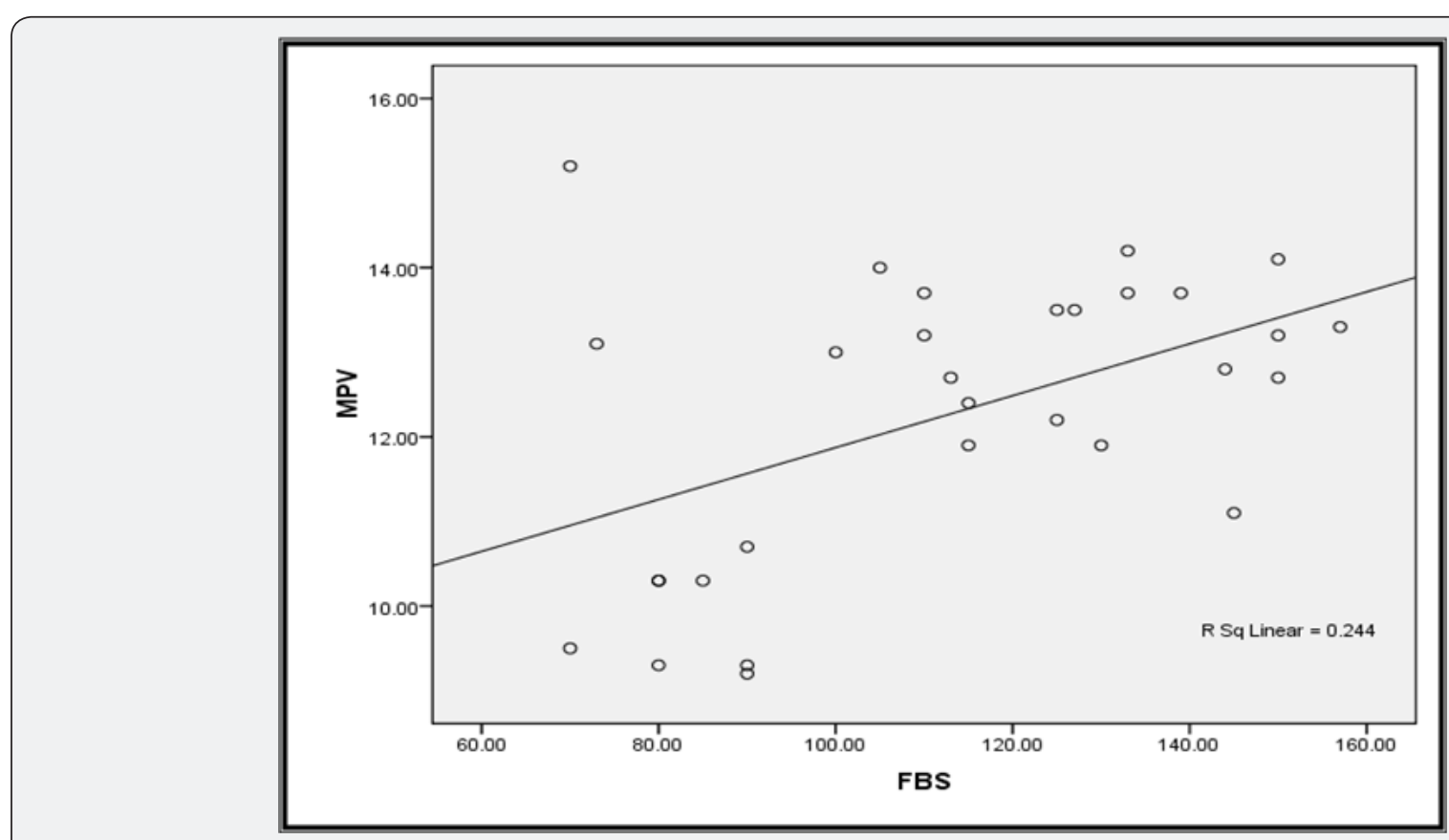

Figure 2: Correlation between MPV at admission and fasting blood sugar.

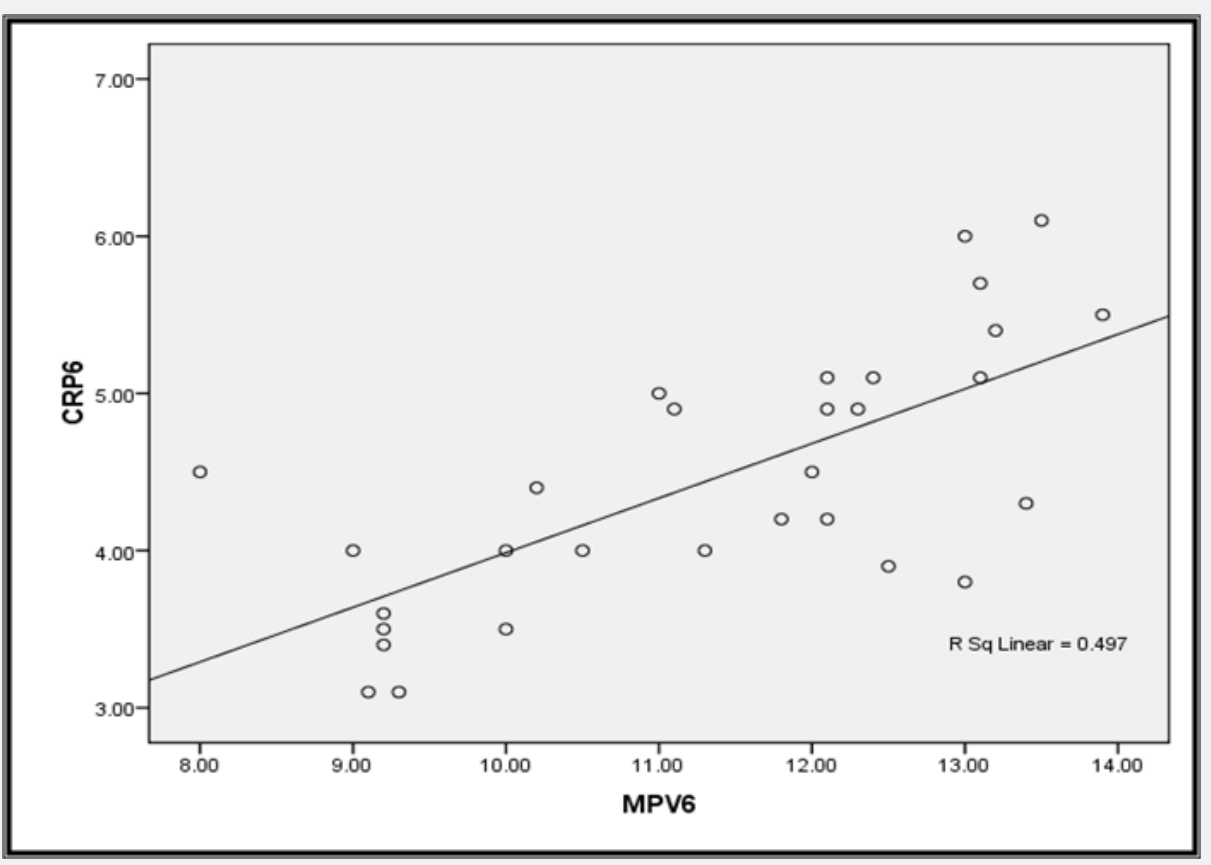

Figure 3: Correlation between MPV after 6 months and CRP after 6 months. 


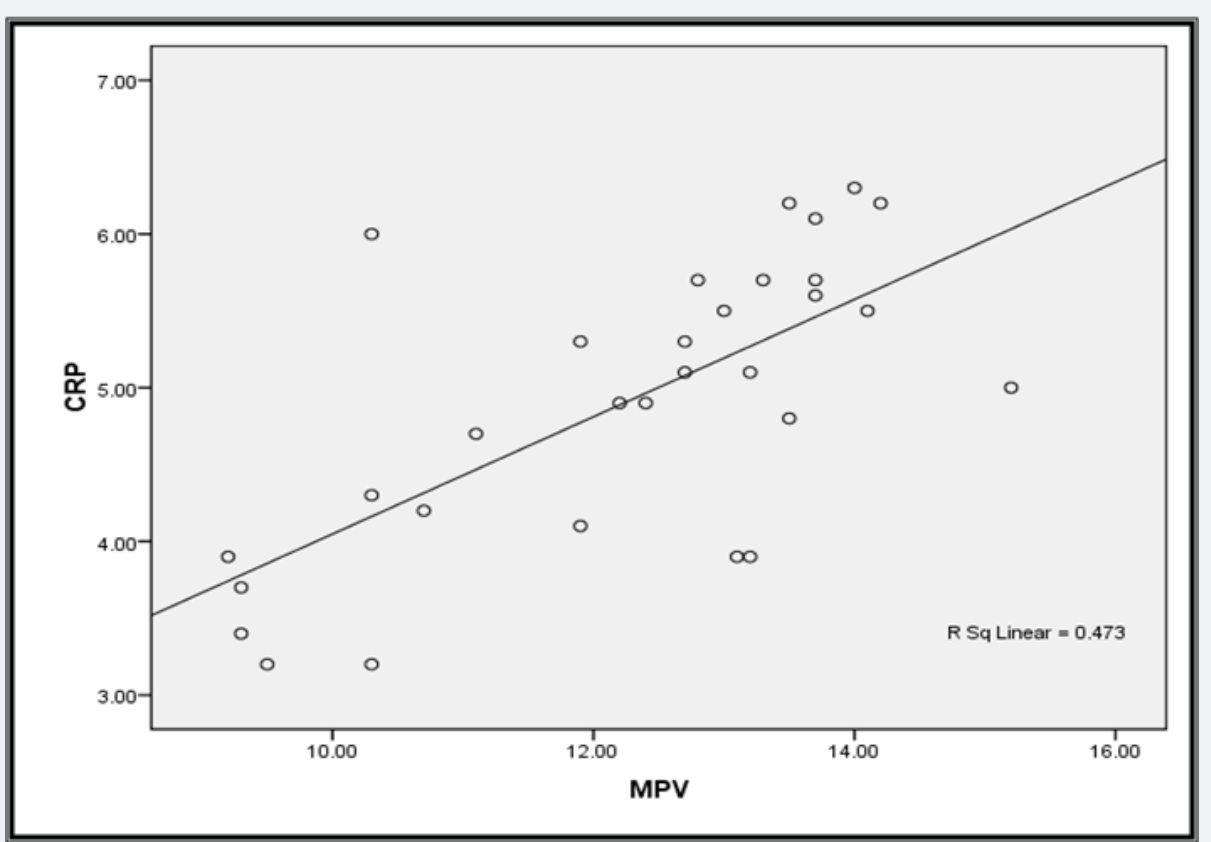

Figure 4: Correlation between MPV and CRP at admission.

Table 5: Correlation between MPV and other parameters in the patients group.

\begin{tabular}{|c|c|c|c|c|}
\hline \multirow{2}{*}{} & \multicolumn{2}{|c|}{ MPV } & \multicolumn{2}{c|}{ MPV 6 } \\
\cline { 2 - 5 } & $\mathbf{R}$ & $\mathbf{P}$ & $\mathbf{P}$ & $0.09(\mathrm{NS})$ \\
\hline LDL & 0.35 & $0.056(\mathrm{NS})$ & -0.368 & $0.046(\mathrm{NS})$ \\
\hline HDL & -0.313 & $0.093(\mathrm{NS})$ & 0.19 & $0.30(\mathrm{NS})$ \\
\hline TC & 0.318 & $0.087(\mathrm{NS})$ & 0.23 & $0.21(\mathrm{NS})$ \\
\hline TG & 0.28 & $0.12(\mathrm{NS})$ & 0.57 & $0.001(\mathrm{~S})$ \\
\hline FBS & 0.49 & $0.006(\mathrm{~S})$ & 0.129 & $0.498(\mathrm{NS})$ \\
\hline ESR & 0.346 & $0.061(\mathrm{NS})$ & 0.55 & $0.002(\mathrm{~S})$ \\
\hline CRP & 0.688 & $0.001(\mathrm{~S})$ & 0.71 & $0.001(\mathrm{~S})$ \\
\hline CRP 6 & 0.59 & $0.001(\mathrm{~S})$ & 0.2 & $0.28(\mathrm{NS})$ \\
\hline IL 6 & 0.16 & $0.20(\mathrm{NS})$ & 0.17 & $0.36(\mathrm{NS})$ \\
\hline IL 6 at 6m & 0.084 & $0.66(\mathrm{NS})$ & & \\
\hline
\end{tabular}

In the present study, there was statistically insignificant difference between different clinical presentations as regard ECG findings or Echocardiographic finding. In addition, there was statistically insignificant difference between different clinical presentations as regard MPV at admission while after 6 months there was proportional (positive), statistically significant correlation between MPV and fasting blood sugar (Figure 2). The same correlation was found between CRP and MPV at the start and at 6 months. The correlation between CRP after 6 months and MPV after 6 months was powerful (Table 5), (Figure 3 \& 4). Finally there was statistically insignificant variance between different clinical presentations as regard IL- 6 at the start and at 6 months (data not presented).

\section{Discussion}

The aim of this study is to evaluate mean platelet volume and some inflammatory markers in patients with slow coronary flow
(SCF) and its possible relationship with clinical presentation. In this study interleukin-6 and C-reactive protein were increased in patients with coronary slow flow in comparison to control group, $P$ value $=(0.031$ and 0.001 respectively $)$, this was in agreement with the study done by [12] which included 42 patients with SCF detected by coronary angiography via the TIMI frame count method and 30 control subjects with angiographically normal coronary flow. The data showed that plasma CRP and IL-6 concentrations were higher in patients with SCF compared with normal control subject $\mathrm{P}$ value $=0.01$.

Consistent with study done by Turhan et al. [14] to evaluate plasma soluble adhesion molecules; intercellular adhesion molecule-1 (ICAM-1), vascular cell adhesion molecule-1 (VCAM1) and E-select in as possible indicators of endothelial activation or inflammation in patients with SCF, but with angiographically proven normal coronary arteries in all three coronary vessels, 
Coronary flow rate of all patients and control subjects were documented by TIMI frame count. The results showed that serum ICAM-1, VCAM-1, and E-selectin concentrations of patients with SCF were found to be significantly higher than those of control subjects with normal coronary flow [14].

In this study we found that mean platelet volume was increased in patients with coronary slow flow in comparison to control group, $\mathrm{P}$ value=0.001; this was in agreement with the study done by [15] which included 50 patients with SCF and otherwise normal coronary arteries were selected for the study group, and 22 patients with normal coronary arteries were selected for the control group, this study proved that MPV is increased in patients with SCF, and SCF patients presenting with USA exhibit significantly increased MPV values, suggesting an altered platelet reactivity and aggregation which may require effective anti-platelet therapy in this patient subgroup. $\mathrm{P}$ value $=0.007$. In previous studies, increased MPV was demonstrated in acute myocardial infarction [16] unstable angina pectoris [1] congestive heart failure [17] and coronary artery ectasia [18].

In this study interleukin 6 and C-reactive protein were decreased after six months of antidyslipidemic drugs $(20 \mathrm{mg}$ atorvastatin) in comparison to their values at the start, $\mathrm{P}$ value $=0.015$. There was study done by [19] which proved that alternate-day dosing of rosuvastatin could be effective comparable with once-daily dosing of rosuvastatin in Chinese patients in improving not only lipid profile but also inflammatory markers (iterleukin 6 and C-reactive protein). There was another study done by [14] which found that short-term (3-12week) treatment with fenofibrate is an effective strategy in the management of elevated CRP concentrations. In study done by [7] which found that statistically significant reduction in CRP after statin treatment in patients with coronary heart disease (CHD) or hyperlipidemia.

In this study mean platelet volume decreased after six months of antiplatelet in comparison to their values at admission. In this study there was no significant difference in mean platelet volume as regard clinical presentation, this disagreement with the study done by [15] which there was significant increase in MPV in patients with SCF presenting with unstable angina. In this study we found that there was no significant difference between patients group and control group as regard clinical presentation $P$ value $=0.34$. This result was the same as the study done by Li et al.

In this study we found that no significant difference in patient group with coronary slow flow and control group as regard systolic function of the left ventricle measured by conventional echocardiography, $\mathrm{P}$ value $=0.18$ but there was significant difference in diastolic function of the left ventricle which were significantly impaired in patients with coronary slow flow compared to the control group by pulsed wave Doppler $P$ value $=0.001$, this was the same result of the study done by [15] which included 22patients (12 males and 10 females) with coronary slow flow and 22 patients(14 males and 8 females) with normal coronary angiography as control group, which found that no significant difference in systolic function of left ventricle measured by conventional echocardiography between patients group and control group, $\mathrm{P}$ value $=0.3$, but that study also found that there was difference in systolic function of the left ventricle measured by tissue Doppler imaging between patients group and control group $\mathrm{P}$ value $=0.001$, this may be due to Tissue Doppler echocardiography is less influenced by several factors such as load condition and PW Doppler mitral inflow velocities.

Seviml et al. [15] found also that there was significant difference in diastolic function of the left ventricle by pulsed Doppler and tissue Doppler between patients group and control group. In this study we found that there was no significant difference between patients group and control group as regard resting electrocardiogram, $\mathrm{P}$ value $=0.23$, this was different from the study done by [20] which included 30 patients with coronary slow flow and 30 patients with normal coronary angiography they found that there were significant changes in resting electrocardiogram in the form of increased $\mathrm{P}$ wave duration and $\mathrm{P}$ wave dispersion in patients group which improved after the use of nebivelol for about 3 months.

In this study we found that there was no significant difference between patients group and control group as regard ESR $P$ value $=0.092$, This was in agreement with study done by $[6,21]$ which included 82 patients with angiographically proven normal coronary arteries and slow coronary flow in all three coronary vessels (45 males and 37 females, mean age $59 \pm 11$ years) and 34 patients with normal coronary arteries and normal coronary flow (19 males and 15 females, mean age $56 \pm 10$ years) with similar risk profiles they found that Hs-CRP and proBNP are significantly higher in patients with coronary slow flow compared with normal control group but no significant difference in ESR between patients group and control group.

As regard LDL and fasting blood glucose levels, In this study we found that there was significant increase in patients group in comparison to control group $\mathrm{P}$ value $=0.001$. Previous studies $[10,12,15,21]$ proved that There were no significant differences between patients with coronary slow flow and control group with normal coronary angiography as regard lipid profile, fasting glucose levels, white blood cell and platelet counts [22-26].

\section{Conclusion}

a) Increased plasma inflammatory markers including CRP and IL-6 existed in patients with SCF. This suggesting that an inflammation may be a contributor for the development of SCF. In other word, increased concentrations of inflammatory markers in patients with SCF may be an indicator of endothelial activation and inflammation and are likely to be in the causal pathway involving in SCF. Despite the relative good prognosis of patients with SCF, the chronic, frequent nature of the persistent chest uncomfortable can significantly impair quality of life. Therefore, an attention should be paid to this unique phenomenon. However, whether increased 
inflammatory markers are related to the pathogenesis of SCF in these patients deserved further investigation.

b) Our findings showed also that MPV is increased in patients with SCF, and SCF patients presenting with USA exhibit significantly increased MPV values, suggesting an altered platelet reactivity and aggregation which require effective anti-platelet therapy in this patient subgroup.

\section{References}

1. Martin JF, Plumb J, Kilbey RS, Kishk YT (1983) Changes in volume and density of platelets in myocardial infarction. Br Med J (Clin Res Ed) 287(6390): 456-459.

2. Yilmaz MB, Cihan G, Guray Y, Guray U, Kisacik HL, et al. (2008) Role of mean platelet volume in triagging acute coronary syndromes. J Thromb Thrombolysis 26(1): 49-54.

3. Bhat T, Teli S, Rijal J, Bhat H, Raza M, et al. (2013) Neutrophil to lymphocyte ratio and cardiovascular diseases: a review. Expert Rev Cardiovasc Ther 11(1): 55-59.

4. Goel PK, Gupta SK, Agarwal A, Kapoor A (2001) Slow coronary flow: a distinct angiographic subgroup in syndrome X. Angiology 52(8): 507 514.

5. Mosseri M, Yarom R, Gotsman MS, Hasin Y (1986) Histologic evidence for small vessel coronary artery disease in patients with angina pectoris and patent large coronary arteries. Circulation 74(5): 964972.

6. Kaya H, Ertaş F, ìslamoğlu Y, Kaya Z, Atılgan ZA, et al. (2014) Association between neutrophil to lymphocyte ratio and severity of coronary artery disease. Clin Appl Thromb Hemost 20(1): 50-54.

7. Li JJ, Wang HR, Huang CX, Xue JL, Li GS (2005) Enhanced response of blood monocytes to C-reactive protein in patient with unstable angina. Clin Chim Acta 352(1-2): 127-133.

8. Alassl M, Sallam A (2015) High pre-operative myocardial ischemia biomarkers as predictors of post-operative mortality after CABG surgery: tertiary center experience. Journal of the Egyptian Society of Cardio-Thoracic Surgery 21(1): 27-34.

9. Fang CH, Li JJ (2004) C-reactive protein is not only an inflammatory marker but also a direct cause of cardiovascular disease. Med Hypotheses 62(4): 499-506.

10. Kalay N, Aytekin M, Kaya MG, Ozbek K, Karayakalı M, et al. (2011) The relationship between inflammation and slow coronary flow: increased red cell distribution width and serum uric acid levels. Turk Kardiyol Dern Ars 39(6): 463-468.

11. Li JJ, Chen XJ (2003) Simvastatin inhibits interleukin -6 release in human monocytes stimulated by C-reactive protein and lipopolysaccharide. Coron Artery Dis 14(4): 329-334.

12. Li JJ, Xu B, Li ZC, Qian J, Wei BQ (2006) Is slow coronary flow associated with inflammation. Med Hypotheses 66(3): 504-508.
13. Gibson CM, Ryan KA, Kelley M, Rizzo MJ, Mesley R, et al. (1999) Methodologic drift in the assessment of TIMI grade 3 flow and its implications with respect to the reporting of angiographic trial results. The TIMI Study group. Am Heart J 137(6): 1179-1184.

14. Turhan H, Saydam GS, Erbay AR, Ayaz S, Yaşar AS, et al. (2006) Increased plasma soluble adhesion molecules: ICAM-1, VCAM-1, and E-selectin concentrations in patients with slow coronary flow. Int J Cardiol 108(2): 224-230.

15. Nurkalem Z, Alper AT, Orhan AL, Zencirci AE, Sari I, et al. (2007) Left ventricular function in patients with coronary slow flow: a tissue Doppler study. Arch Turk Soc Cardiol 35: 360-365.

16. Endler G, Klimesch A, Sunder-Plassmann H, Schillinger M, Exner $\mathrm{M}$, et al. (2002) Mean platelet volume is an independent risk factor for myocardial infarction but not for coronary artery disease. $\mathrm{Br} \mathrm{J}$ Haematol 117(2): 399-404.

17. Erne P, Wardle J, Sanders K, Lewis SM, Maseri A (1988) Mean platelet volume and size distribution and their sensitivity to agonists in patients with coronary artery disease and congestive heart failure. Thromb Haemost 59(2): 259-263.

18. Bitigen A, Tanalp AC, Elonu OH, Karavelioglu Y, Ozdemir N (2007) Mean platelet volume in patients with isolated coronary artery ectasia. J Thromb Thrombolysis 24(2): 99-103.

19. Li JJ, Yang P, Liu J, Jia YJ, Li ZC, et al. (2012) Impact of 10mg rosuvastatin daily or alternate- day on lipid profile and inflammation markers. Clin Chim Acta 413(1-2): 139-142.

20. Gunes Y, Tuncer M, Guntekin U, Ceylan Y (2009) The effects of nebivolol on $\mathrm{P}$ wave duration and dispersion in patients with coronary slow -Original Investigation. Anadolu Kardiyol Derg 9(4): 290-295.

21. Madak N, Nazlı Y, Mergen H, Aysel S, Kandaz M, et al. (2010) Acute phase reactants in patients with coronary slow flow phenomenon. Anadolu Kardiyol Derg 10(5): 416-420.

22. Kopetz V, Kennedy J, Heresztyn T, Stafford I, Willoughby SR, et al. (2012) Endothelial function, oxidative stress and inflammatory studies in chronic coronary slow flow phenomenon patients. Cardiology 121(3): 197-203.

23. Gary T, Pichler M, Belaj K, Hafner F, Gerger A, et al. (2013) Plateletto-lymphocyte ratio: a novel marker for critical limb ischemia in peripheral arterial occlusive disease patients. PLoS One 8(7): e67688.

24. Li JJ (2005) Inflammation: an important mechanism for different clinical entities of coronary artery disease. Chin Med J 118(21): 18171826.

25. Ye J, Kiage JN, Arnett DK, Bartolucci AA, Kabagambe EK (2011) Short -term effect of fenofibrate on C-reactive protein: A meta analysis of randomized controlled trials. Diabetol Metab Syndr 3: 24.

26. Nurkalem Z, Alper AT, Orhan AL, Zencirci AE, Sari I, et al. (2008) Mean platelet volume in patients with slow coronary flow and its relationship with clinical presentation. Turk Kardiyol Dern Ars 36(6): 363-367. 

CC (i) Commons Attribution 4.0 License BY DOI: $10.19080 / J O C C T .2018 .10 .555784$
Your next submission with Juniper Publishers will reach you the below assets

- Quality Editorial service

- Swift Peer Review

- Reprints availability

- E-prints Service

- Manuscript Podcast for convenient understanding

- Global attainment for your research

- Manuscript accessibility in different formats

( Pdf, E-pub, Full Text, Audio)

- Unceasing customer service

Track the below URL for one-step submission https://juniperpublishers.com/online-submission.php 